\title{
Perceiving the political landscape: ego biases in cognitive political networks
}

\author{
Jeffrey C. Johnson ${ }^{\mathrm{a}, *}$, Michael K. Orbach ${ }^{\mathrm{b}}$ \\ a Department of Sociology, East Carolina University, Brewster A-416, 10th Street, Greenville, NC 27858, USA \\ b Duke University, Durham, NC, USA
}

\begin{abstract}
Recent studies have found that individuals tend to see themselves as more central in a network than they really are. This body of work has generally been done among small groups of $<30$ actors. Additionally, settings have usually been in a well-bounded social context focusing on friendship or work relations. Other related research has found links between activity and influence in a network and accurate knowledge of the network. This paper brings together these areas of research on bias and accuracy in the study of a moderate sized legislative political network involving legislators, agency heads, lobbyists, industry representatives, and agency and legislative staff. In a setting where accuracy in an understanding of the political landscape has important implications, the study finds variation in cognitive network bias is patterned with respect to social knowledge, centrality, and an actor's status in the political network. () 2002 Elsevier Science B.V. All rights reserved.
\end{abstract}

Keywords: Political network; Lobbyists; Actor

\section{Introduction}

In a series of articles on informant accuracy Bernard and Killworth (1977), Killworth and Bernard (1976, 1979/1980) and Bernard et al. (1980, 1982) [referred to as BKS] questioned the ability of informants to report accurately on their interactive behavior with others. Through their studies of such groups as HAM radio operators, fraternity house residents, and deaf Teletype users, BKS found little overlap between informant's reports of who they said they interacted with and behavioral observations of actual interactions. Although BKS were certainly not the first to report a lack of correspondence between reported and observed behavior, their findings seemed to question further social scientists' long running use of verbal reports of behavior as a proxy for actual behavior. In response to the findings

\footnotetext{
* Corresponding author. Tel.: +1-252-328-1076; fax: +1-252-328-4837.

E-mail address: johnsonje @ mail.ecu.edu (J.C. Johnson).
} 
of BKS, a number of individuals initiated research on the relationship between what people say and what they actually do, and their work not only led to an increased understanding of informant accuracy more generally, but led to other related work as well.

Romney and Faust (1982), in their reanalysis of the some of the BKS data sets, found that informant accuracy depended on an informant's frequency of interaction in the groups; active group members were more accurate in their reports. This was followed by Romney and Weller (1984), who found that informant accuracy is even more a function of informant reliability or the correlation of each informant's response to the group aggregate. In a direct effort to understand informant accuracy, Freeman and Romney (1987) in a study of a university colloquia series found that informants' reports of behavior are influenced by long-term patterns and do accurately reflect the usual and regular behaviors of group members (Freeman et al., 1987). Thus, people's reports of behavior are biased with respect to long-term patterns of the observed behavior of others. Yet other studies linked variations in accuracy and knowledge of networks to such factors as social rank (Boster et al., 1987), reputation (Krackhardt, 1990) and network centrality in organizations (Brass, 1985).

Related to, and somewhat stimulated by, the work on accuracy of actor's understanding of the structure of social networks is work on the perception of an actor as to his/her place within the network. Often an actor can be accurate concerning judgments or perceptions of the place of others in a given system, but fail to report accurately on his or her own place, status, behavior, characteristics, etc. Again, social scientists have long reported on these tendencies or biases in a variety of non-network settings and with regard to a variety of types of social perceptions or judgments. Additionally, such biases have overwhelmingly been in the direction that places ego in a more positive or favorable light. Thus, people have a tendency to see themselves more favorably than do others in terms of, for example, intelligence (Cogan et al., 1915), social class position (Warner et al., 1960), work effort (Ross and Sicoly, 1979), personality (Iannucci, 1991), and dominance (Omark et al., 1975). In research related more directly to ego's perception of their place in the network there is a clear body of evidence that actors tend to over report ties to actors of higher status. In a comparison of reported and observed network ties among 23 members of an accounting firm, Webster (1995) found that unreciprocated and unobserved ties were predominantly directed at actors of higher status, in this case the firm's partners (see also Freeman and Webster, 1994).

Particularly important to the study reported here is the work of Kumbasar et al. (1994). In the study of a department at a computer company they had each of 25 actors report on, not only his or her friends, but also the friendships among all other actors in the network. Introduced by Newcomb (1961) and formalized by Krackhardt (1987, 1990), these cognitive networks reflected each actor's perception of the friendship relations in the group. They found that actors see themselves as more central in the network than they really are and report more transitive triples, more ties, and more reciprocated ties among friends than among those not reported as friends.

The findings of Kumbasar et al. (1994) and others are compelling in terms of the evidence of a systematic bias in ego's social perception of centrality. But can we expect that such systematic biases in perceived centrality will hold across all networks or categories of network actors? Are there social or political contexts in which incentives or consequences may limit or constrain such biases? In pursuit of answers to these questions, this paper examines ego biases in social perceptions among actors in a political network. In contrast to earlier 
research, this study explores variations in bias in a weakly bounded, issue-oriented political network of moderate size. In addition, we focus primarily on the perceived centrality of actors in the network.

\section{The political network}

The number of crabpots in North Carolina waters doubled from 300,000 in the mid 1980's to over 600,000 by 1990 (Johnson and Orbach, 1996). NC crabbers' league of aware watermen (C.L.A.W.) pressured state legislators to take notice of crab fishery problems resulting from increasing numbers of fishers and gear. By 1991 the state legislature placed a moratorium on new crab licenses in the state. These efforts in the crab fishery drew attention to increasing problems of declining fish stocks, increased effort, and pollution throughout North Carolinas' other important fisheries. By 1 July 1994 the legislature enacted House Bill 1540 which specified a 2 year moratorium on the sale of new commercial fishing licenses and established the Moratorium Steering Committee charged with developing a management reform package for North Carolina fisheries.

The political network that is the focus of this study involved individuals who were central to both the passing of this legislation and the initial attempt to organize and develop a management reform package. Bounding a network of this kind is challenging, particularly with respect to keeping the network large enough to gain a valid understanding, yet small enough to facilitate the collection of cognitive network data. Initially five key actors in the political network were identified and interviewed. They were asked to list "all individuals they saw as important in the moratorium process". The five resulting lists were compared for overlap and the 44 most common names were selected for inclusion in the study. Included were four primary statuses of actors that we will refer to as legislators (L), managers (M), staff $(\mathrm{S})$, and private $(\mathrm{P})$.

The legislator group consisted primarily of coastal representatives and senators but also included chairs, co-chairs, and members of key legislative committees (e.g. Seafood and Aquaculture Committee), legislative members of the Moratorium Steering Committee, a representative that was a former secretary of an important state department, and the President Pro Tem of the Senate (The President Pro Tempore (Tem) of the Senate presides over the State Senate in the absence of the President of the Senate, the Lieutenant Governer of North Carolina). Staff designees included legislative staff, state departmental staff, divisional liaisons to the steering committee, and lawyers from the Attorney Generals' office. Private sector actors included commercial fishing industry representatives and industry association board members, citizen members of relevant legislative committees including the Moratorium Steering Committee, executive directors of recreational and commercial groups, and fishermen auxiliary members. Finally, managers consisted of directors of state agencies, members of the North Carolina Marine Fish Commission (the regulatory committee for state fisheries management), committee chairs, head, deputy head, and assistant head for a relevant state department, and the director of a joint state/federal research agency.

Interviews were primarily conducted in the offices of the various actors. The interviews began shortly after the passing of the legislation initiating the process and the institution of the Moratorium Steering Committee in late 1994. It is important to note that the collection 
of network data, particularly the cognitive network data, was extremely challenging given the time constraints of many of the network members. It was therefor critical to keep the interview as short as possible.

\section{The data}

This section describes the measures used in the analysis. The measures were primarily derived from two components of the interviews. The first involved political actors rating of their own communication interactions with other network members. The second involved a political actor's perception of communication interactions among all members of the network. These two sources of data were used to develop the following measures.

\subsection{The 'reported' network}

Each of the political actors were asked to rate their interactions with each of the $n$ - 1 other actors on a scale from 0 to 10 in terms of discussing matters related to the license moratorium. The reported network $\boldsymbol{R}$ is a $44 \times 44$ matrix in which cell $(i, j)$ of $\boldsymbol{R}$ denotes the strength of reported communication interaction from actor $i$ to actor $j$. It is important to note the use of these relations as the gold standard for comparison (e.g. often referred to as the 'true' network). In other studies of this type the observed network is generally derived from an aggregation of $N$ cognitive matrices to form the standard for comparison. We discuss this in somewhat more detail in Section 3.7.

\subsection{Cognitive networks}

Each political actor was asked, in a pick $k$ design, to determine the three actors each of the $N$ actors listed, including themselves, talked to most concerning the commercial license moratorium. Thus, outdegree is the same for all actors (although it should be noted that some actors had difficulties providing three names for some of the actors). This leads to 44 digraph matrices, $\boldsymbol{X}_{i}$, each of size $44 \times 44$, one for each of the actors in the network (Krackhardt, 1987). Kumbasar et al. (1994) recommend such a fixed choice design in pursuit of "a cleaner measure of structural biases". We employ such a design for practical (i.e. minimizing the labor intensive nature of the task for this special population) as well for the theoretical reasons discussed by Kumbasar et al. (1994).

\subsection{Knowledge of the network}

Accuracy or knowledge of the network is determined through a QAP correlation of each of the individual cognitive matrices, $\boldsymbol{X}_{i}$, with the 'reported' matrix of ratings of interactions, $\boldsymbol{R}$ (Hubert and Schultz, 1976).

\subsection{Reported indegree centrality}

Based on ratings on a scale from 0 to 10 of the extent to which each $i$ and $j$ had informal discussions with others on topics related to the license moratorium, rows of the reported 
matrix were normalized and the column totals of $\boldsymbol{R}$ calculated representing a normalized ratings indegree centrality. The row entries for the matrix were row normalized ( $z$ scores) to deal with potential problems stemming from variations in actor's subjective use of the ratings scales. The scales were normalized to improve the measures psychometric meaningfulness (see Eudey et al. (1994) for a discussion).

\subsection{Cognitive indegree centrality}

This is the indegree centrality of actors in each of the cognitive networks including ego. Column totals for each $\boldsymbol{X}_{i}$ are equal to the nodal indegrees or the sum of $j$ 's communications with $k$ as perceived by $i$. All indegree centralities are reported as normalized scores as calculated using UCINET (Borgatti et al., 1999).

\subsection{Accuracy}

Aside from the QAP correlations for determining knowledge, each actor's accuracy in estimating actor's centralities was determined by the magnitude of the correlations between the cognitive indegree centrality and the reported indegree centrality across all actors.

\subsection{Bias}

We measure ego bias with regard to centrality in two ways. The first measure involves the difference between an actor's ranked indegree centrality in their cognitive network (the nodal indegree for actor $i$ in $\boldsymbol{X}_{i}$ ) and the ranked normalized ratings centrality or the reported centrality (the normalized ratings indegree centrality for actor $i$ in $\boldsymbol{R}$ ). The second is based on ego's residual in a regression of indegree cognitive centralities from ego's cognitive network with reported centrality. For both measures positive values denote bias downward (i.e. less central than ego really is) while negative values denote bias upward (i.e. more central then ego really is).

We need to return briefly to issues concerning rationales for choosing a network standard for comparison with the individual cognitive networks. Kumbasar et al. (1994) and others have generally used aggregate cognitive matrices as the standard for comparison. Although aggregate cognitive data of this kind is generally robust, particularly for such things as semantic domains, it is important to consider problems of accuracy in low social information environments, particularly in contexts where there are high degrees of status differentiation. Most previous research on cognitive bias has involved study contexts with high information environments, that is social environments where actors might be expected to have reasonable knowledge about the relations and social behaviors of other actors. This has been due in part to the limited size of study groups, the high degree of spatial proximity of group members, and the focus on friendships or relations concerning sociability. This poses the interesting question concerning the presence of systematic biases in standards for comparison in different information environments. In high information environments, like offices, there may be a tendency for each ego to over-estimate the number of ties with high status actors (Webster, 1995). These individual biases, however, will tend to be canceled out when ego perceptions' are aggregated across all egos, thus, leading to a more robust 


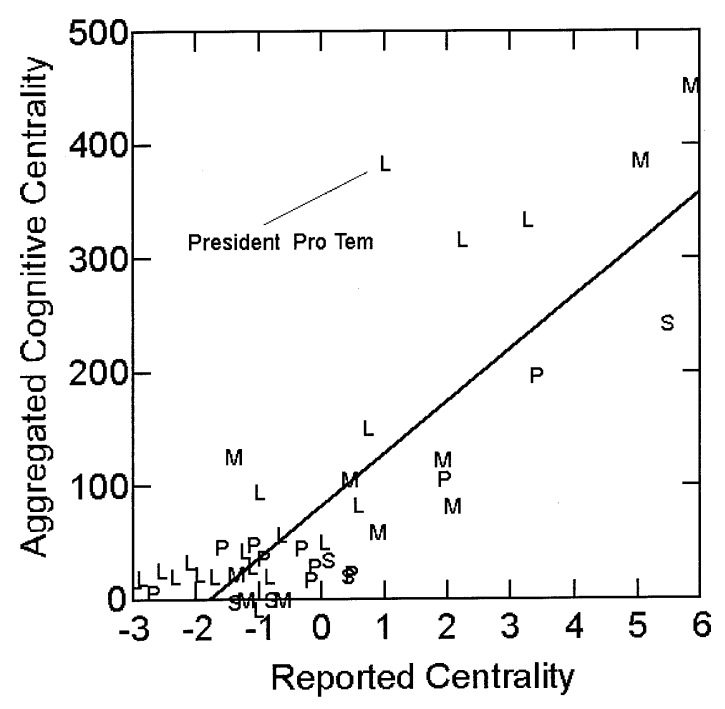

Fig. 1. Scatterplot of reported centrality and indegree centrality from the aggregated cognitive network (indegree centralities are reported as normalized indegrees as calculated using UCINET, legislator (L), manager (M), staff $(\mathrm{S})$, and private $(\mathrm{P}))$.

overall estimate of the network of relations (see Kumbasar et al., 1994). However, in low information environments, like the geographically and socially diffuse issue-oriented political network described here, egos may not only have a tendency to over-estimate their ties to high status actors, but may also over-estimate other actors ties to high status actors, thus, producing systematic biases that would not be cancelled out when individual estimates are aggregated. Simply, in the presence of only limited observations and knowledge of the social interactions of others, egos may rely on status, or other attributes, as a reasonable proxy for estimating the extent of social interactions among other less familiar actors, possibly leading to systematic biases in the aggregate measure.

In a comparison of data from two possible standards, Fig. 1 is a scatterplot comparing reported indegree centrality obtained from the reported normalized ratings network with indegree centrality obtained from an aggregation of the individual cognitive networks. The two measures are highly intercorrelated (Pearson's $r=0.831, P<0.0001$ ) reflecting a good degree of agreement for the two separate, but related measures. However, the legislator to the upper left is an outlier (studentized residual $=4.332$ ) in a regression of the two measures (Pearson $r=0.866, P<0.0005$ with outlier removed). The residual lies to the aggregated cognitive side of the regression line. This actor is the President Pro Tem of the Senate and is the leading and formally most powerful Senator independent of network context. This difference might be accounted for in a spillover of influence from a multitude of other network contexts (e.g. budget baffles, school bond issues, etc.) into this loosely bounded issue-oriented network, thus, tending to over inflate the centrality in the cognitive networks of this extremely high formal status actor. This actor's centrality in the reported network is much lower and tends to be more in accordance with ethnographic 
observations of network participation. Our proposition concerning the two measures certainly needs further investigation, but for the purposes of this article we employ the reported ratings of communication as the standard for comparison. We do this in hopes of gaining a better understanding of the convergent validity of these two separate but related measures. Additionally, we concentrate exclusively on indegree centrality for comparison. Whereas Kumbasar et al. (1994) examined four centrality measures (indegree, outdegree, betweenness, and closeness) our fixed choice methodology and our concern for the robustness of the various centrality measures, particularly betweenness centrality, lead us to concentrate, at least in this article, on indegree centrality.

\section{Results}

\subsection{Accuracy}

The work of Romney and Faust (1982) and Brass (1985) discussed earlier would suggest an association between centrality and knowledge of the network. In a comparison of ego's knowledge of the network with reported centrality (i.e. normalized ratings centrality) there is a moderately strong linear relationship $(r=0.662, P<0.0005)$, particularly with the removal of a single outlier $(r=0.728, P<0.0005)$. Fig. 2 is a scatterplot comparing the two variables and reveals that legislators, as a status, tend to be the least central and have the least amount of knowledge of the network $(\bar{X}=0.161$, S.D. $=0.08)$ followed by $\operatorname{staff}(\bar{X}=0.212$, S.D. $=0.09)$, managers $(\bar{X}=0.238$, S.D. $=0.11)$ and private citizens $(\bar{X}=0.264$, S.D. $=0.04)$. Fig. 3 is a boxplot comparing knowledge of the network across the four groups and additionally showing the distribution of the individual

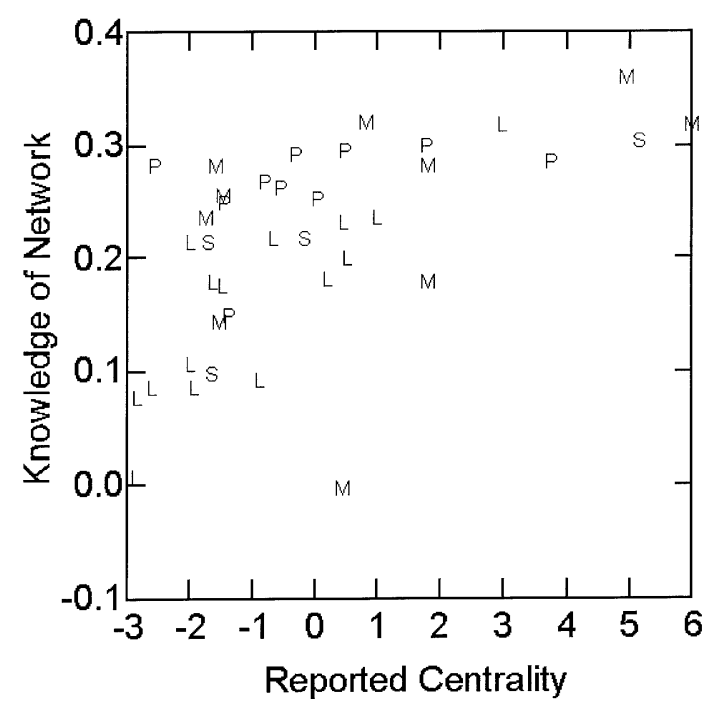

Fig. 2. Scatterplot of reported centrality and knowledge of the network. 


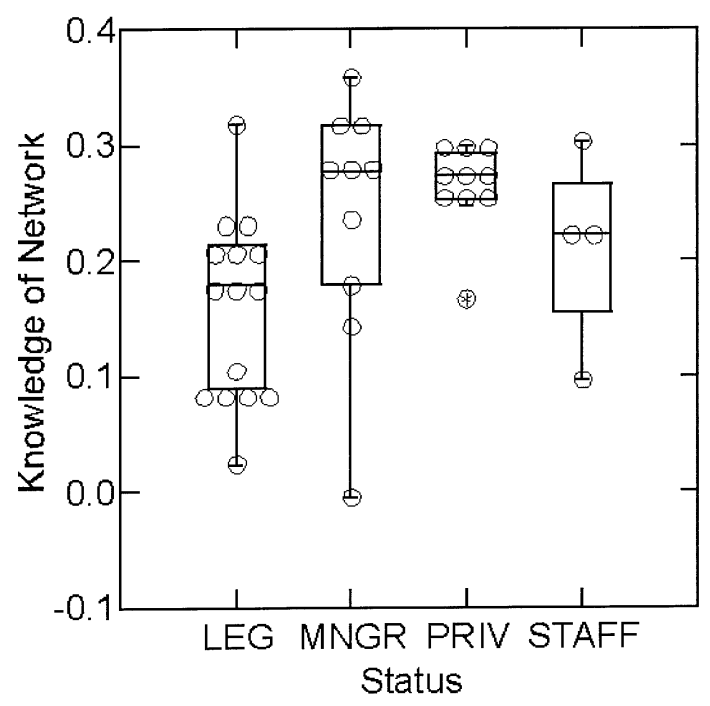

Fig. 3. Box plot of knowledge of the network by status.

data points. There is a significant difference among the groups in terms of knowledge $(F$ $(3,35)=3.765, P<0.02)$ where the primary difference is between the legislators and the private actors (Tukey HSD, $P<0.02$ ). Although these differences might appear to be attributable to differences in reported centrality, no differences were found between groups $(F(3,40)=1.73, P<0.2)$.

In another examination of variation in knowledge and accuracy we now turn to a comparison of the correlations of indegree cognitive centrality with reported centrality. Fig. 4 is a boxplot of the correlations showing the distribution of $r$ 's for each group. Similar to the analysis above, there is a significant difference between the four statuses $(F(3,35)=4.552$, $P<0.01)$ with a post hoc test revealing a difference between legislators and private actors (Tukey HSD, $P<0.01$ ). What is particularly intriguing is the small amount of variability among actors in the private status. Private actors all had moderately high correlations showing a higher degree of correspondence between the cognitive and the reported.

\subsection{Bias}

A comparison of ranked cognitive centrality and ranked reported centrality (Fig. 5) reveals that there is a greater tendency for egos to overestimate their centrality (paired $t$ (38) $=$ $-3.975, P<0.0005)$. However, there are a smaller number of egos that have a tendency to underestimate, although the magnitudes of the underestimates are relatively small compared to those actors who overestimate. Approximately $12.8 \%$ of egos were within plus or minus one rank while $18 \%$ underestimated and $64 \%$ over-estimated centrality. It is important to note that even in Kumbasar et al. (1994), approximately $20 \%$ of the actors did not over report their own ties to other actors. As is evident in the figure, the most extreme biases occur among several of the legislators in the lower right of the plot. In a comparison of 


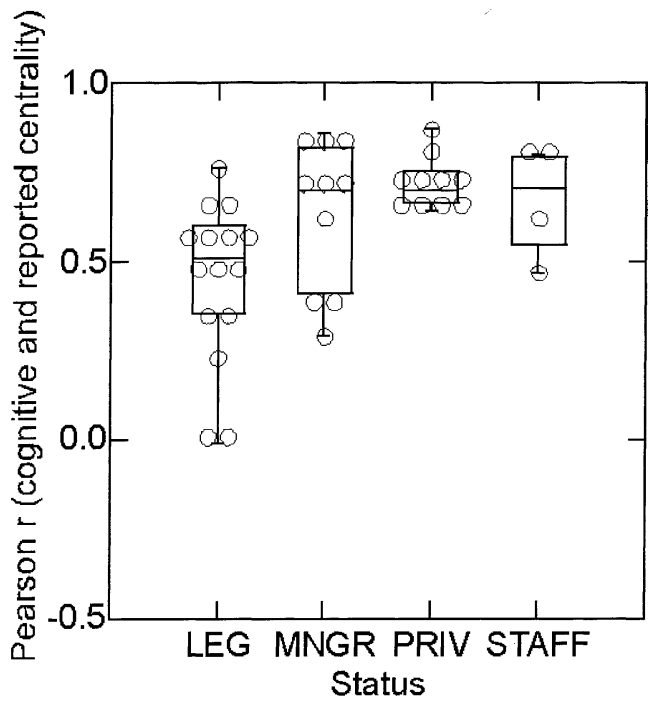

Fig. 4. Box plot of correlation's between cognition and reported centrality by status.

status by bias, Fig. 6 is a box plot of the differences between the ranking of ego's centrality and the ranking of ego's reported centrality. There is a tendency for legislators followed by staff to see themselves as more central at a higher proportion than any of the other groups, although the differences are not significant $(F(3,35)=2.457, P<0.08)$.

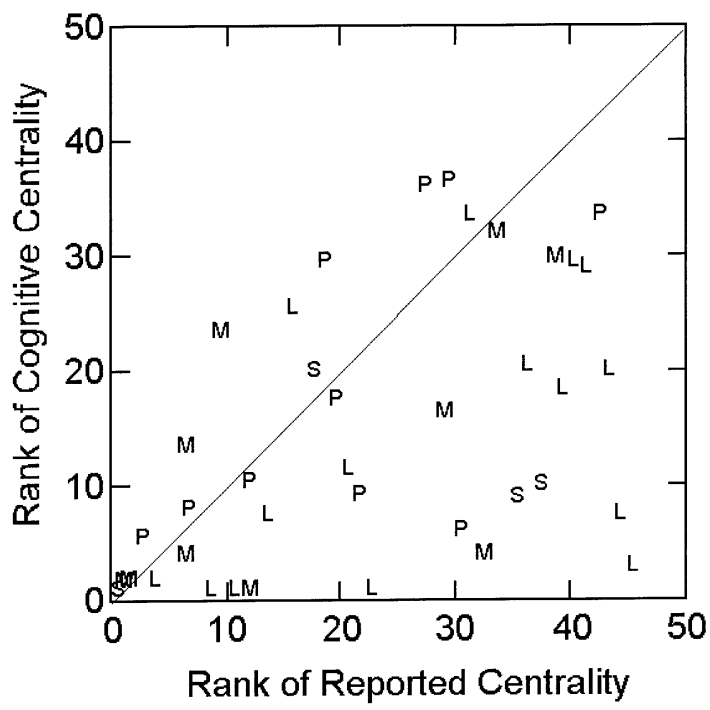

Fig. 5. Scatterplot of ranked reported and cognitive centrality. 


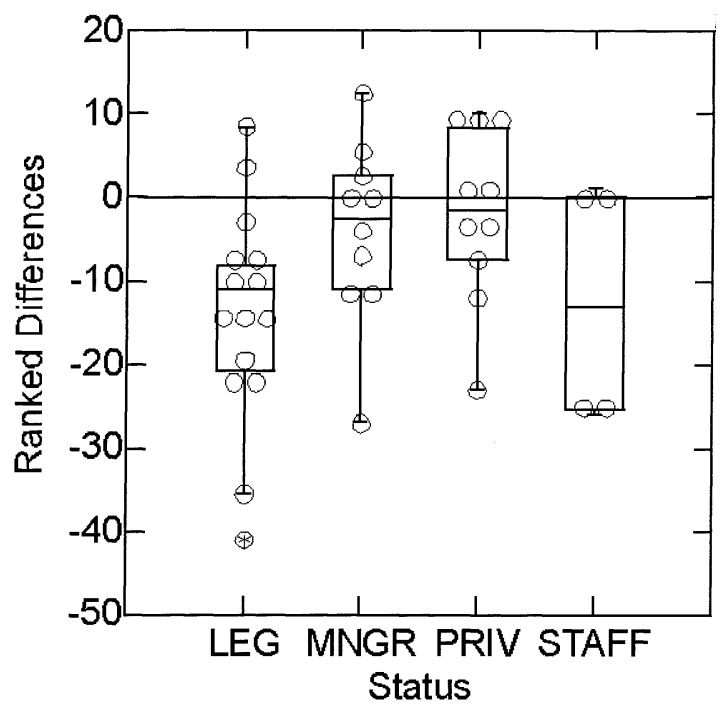

Fig. 6. Box plot of ranked differences by status.

In a further examination of bias, the residuals for each ego's centrality in their own cognitive network from the regressions with the reported centralities were compared. The pattern of residuals for the groups is similar to the previous figure $\left(r_{\text {rank differences } \times \text { residuals }}=0.814\right.$, $P<0.0005)$ in that bias upward is found primarily among the legislators while bias down is found primarily among private actors and to a lesser degree among managers. In this instance, there is a statistically significant difference among the statuses in terms of the residuals $(F(3,34)=4.191, P<0.02)$ with the difference being primarily between the legislators and the private actors (Tukey HSD, $P<0.02$ ).

In a further examination of ego bias it is important to look at the relationship between bias in ego centrality and both knowledge of the network and reported centrality. Fig. 7 is a scatterplot of the ranked differences for centrality with ego's knowledge of the network. There is a clear linear relationship $(r=0.638, P<0.0005)$ revealing, not surprisingly, that the more knowledgeable an actor the smaller the ego bias. Further, if bias downward occurs, it only occurs among the most knowledgeable actors. Among less knowledgeable actors bias is always upward possibly reflecting an ego's need to place oneself and proximate actors as more central in the network due to a limited understanding of the bigger picture (i.e. under conditions of ignorance, ego and ego's proximate actors become disproportionately more important).

As we saw in the previous section, there was a relationship between activity in the network and an accurate understanding of the network $(r=0.728, P<0.0005)$. Similarly, when we compare ego bias with activity or the reported centrality of actors in the network we find that the lower an actor's centrality the greater the bias $(r=0.536, P<0.0005)$. Fig. 8 is a scatterplot of the relationship between the two variables revealing an important pattern among the actors. The figure clearly shows that as reported centrality increases bias declines to at or near zero. The most central actors display the least bias in ego centrality. 


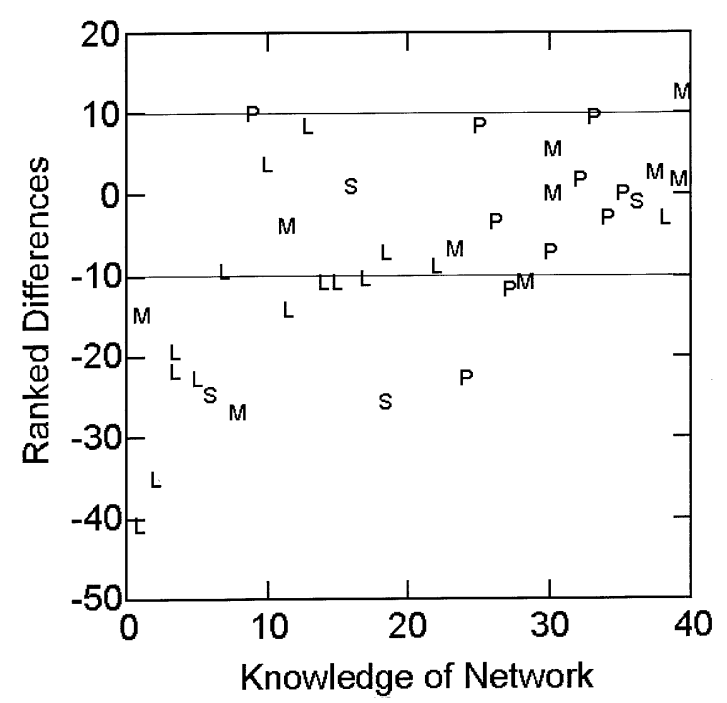

Fig. 7. Scatterplot of ranked differences by knowledge of the network.

More importantly, as centrality increases ego bias converges on zero following to some extent a logistic curve. Also, centrality at the low end is generally associated with upward bias in ego assessments of centrality, but as centrality increases slightly there is a corresponding decrease in the degree of bias. However, bias at this point can go in either an upward or downward direction.

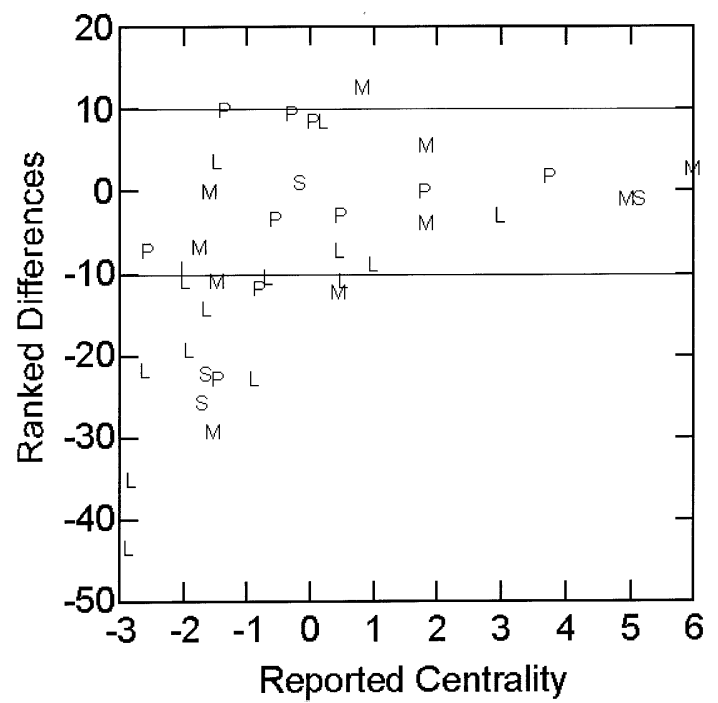

Fig. 8. Scatterplot of ranked differences by reported centrality. 


\section{Examples of bias and accuracy}

In this section we provide various examples of accuracy and bias for specific actors in the network. Examples include two actors with high accuracy/high bias, two actors with high accuracy/low bias, and two actors with low accuracy/high bias in which biases can be both upward and downward. The fourth possible outcome of low accuracy/low bias was not observed suggesting that in the absence of accurate information on relations among members of the network actors are overly reliant on the structure of proximate relations leading to high upward bias in reporting on the relations of both ego and ego's reported relations.

\subsection{Example 1: high accuracy/high bias}

The first two examples illustrate actors with high to moderately high accuracy/knowledge but with high bias, one in the upward direction and the other downward. Fig. 9 is a scatterplot showing the relationship between reported centrality and the cognitive indegree centrality from the cognitive network of actor three. Actor three is probably the single most powerful legislator in the network overall (i.e. across many issue-oriented networks) and was moderately central in the observed network. His/her understanding of the relations among the actors is moderately high (QAP knowledge rank $=19, \mathrm{r}=0.596$ ) and the figure reveals a moderate linear relationship between reported and cognitive centrality. However, actor three displays a high bias upwards in terms of his/her own centrality in the cognitive network even though this actor has moderately high centrality in the reported network (ego's residual $=-3.133$, ranked difference $=-9$ ).

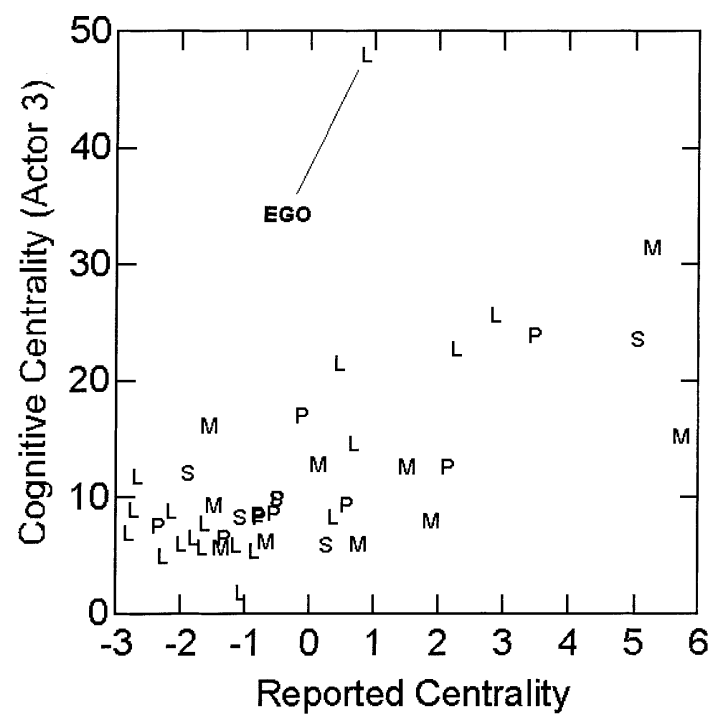

Fig. 9. Scatterplot of cognitive and reported centrality for actor three with ego's position indicated. 


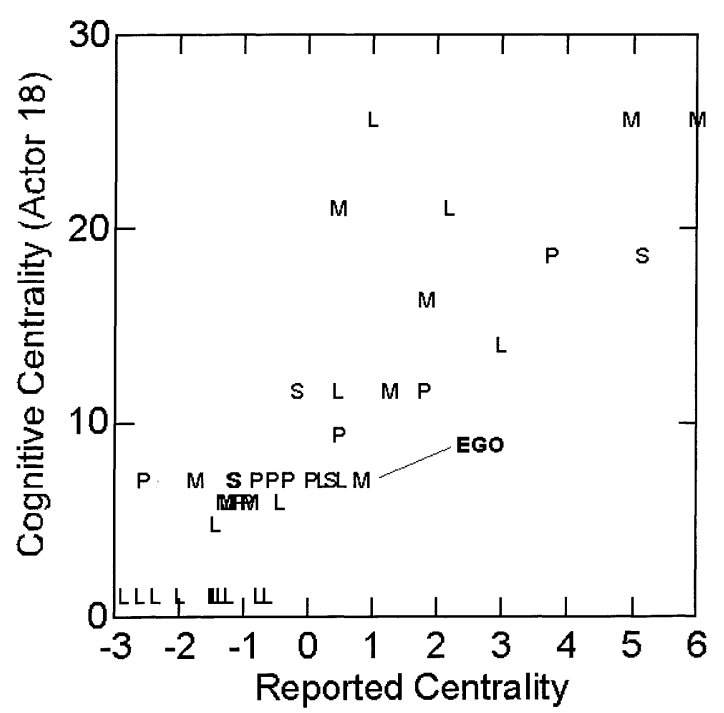

Fig. 10. Scatterplot of cognitive and reported centrality for actor 18 with ego's position indicated.

The second of the two examples in this section involves an actor with high accuracy/knowledge and high bias but in the downward direction. Fig. 10 is a scatterplot of reported versus cognitive centrality for actor 18. Although not as powerful as actor three, actor 18, a manager, is a state agency liaison to an important regulatory committee and was moderately central in the reported network. As such, his/her responsibilities dictated frequent contact among the various committees involved in the moratorium process facilitating a high degree of opportunity to observe interactions among the various players in the network. Actor 18 has high accuracy (QAP knowledge rank $=2$, $r=0.839$ ) but has high bias downward (ego's residual $=1.143$, ranked difference $=$ 12.5).

\subsection{Example 2: high accuracy/low bias}

The next two examples illustrate actors with both high accuracy and low bias. The first example is for actor 28, a manager, who is the chair of two important committees and was highly central in the reported network (Fig. 11). A key figure in the moratorium process, actor 28 was in attendance at all meetings relevant to moratorium issues whether in a public setting in various places around the state or in the State House itself. His/her accuracy was the highest in the network (QAP knowledge rank $=1, r=0.858$ ) while bias was close to zero (ego's residual $=-0.306$, rank difference $=-1$ ).

The second example also shows an actor with high accuracy and low bias but who has moderate centrality in the reported network. Actor five, a private participant, is the executive director of an important fisheries group in the state that that has connections to a large regional association that is politically active (Fig. 12). As a representative of a special 


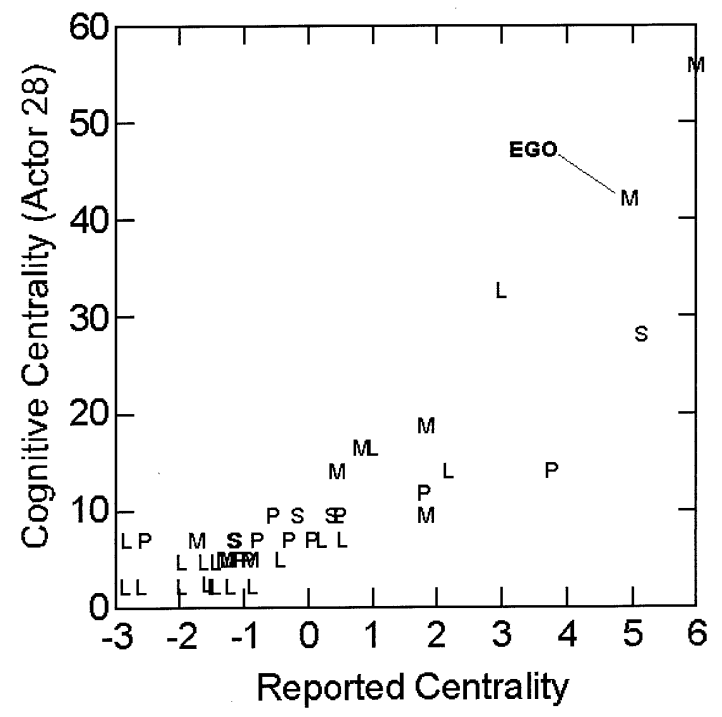

Fig. 11. Scatterplot of cognitive and reported centrality for actor 28 with ego's position indicated.

interest group, actor five attended most of the meetings associated with fisheries issues, whether directly related to the moratorium or not. Actor five's accuracy was relatively high (QAP knowledge rank $=7, r=0.868$ ) while his/her bias was low (ego's residual $=0.487$, rank difference $=-3$ ).

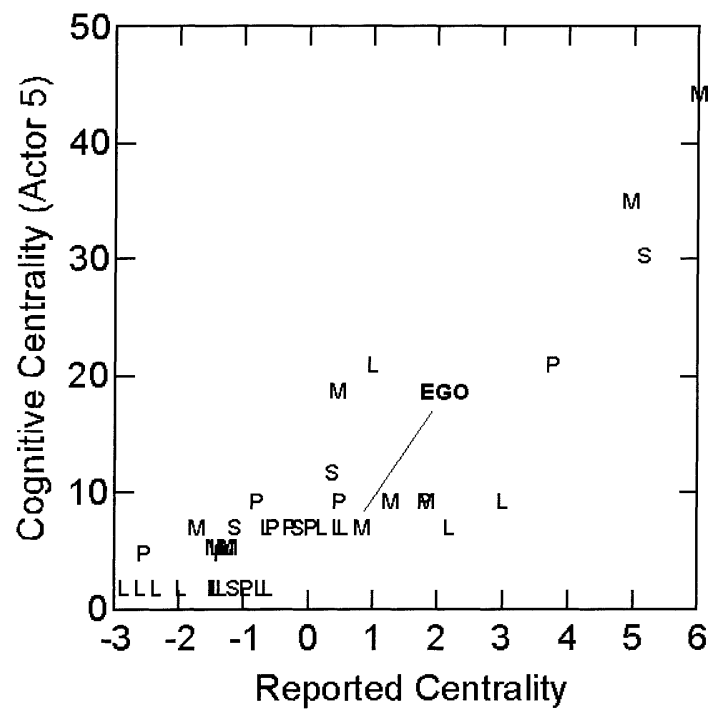

Fig. 12. Scatterplot of cognitive and reported centrality for actor five with ego's position indicated. 


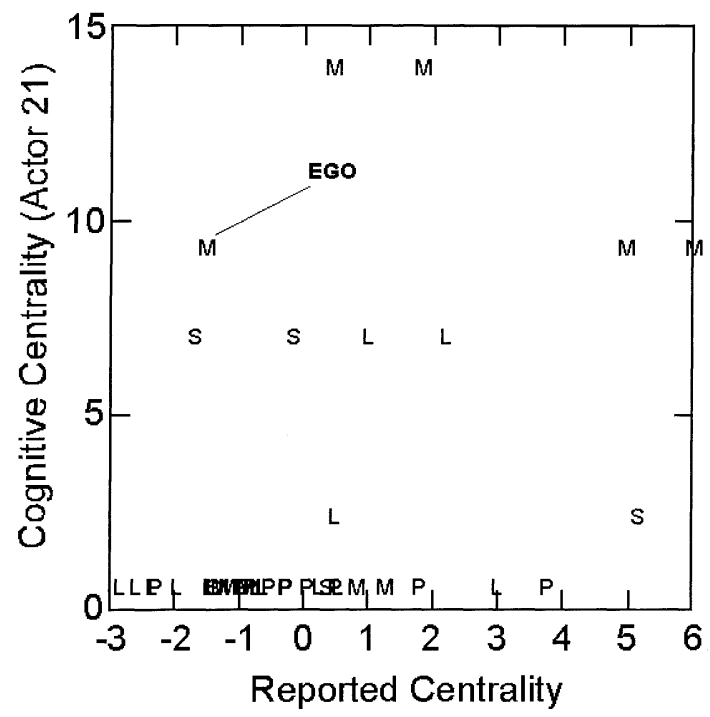

Fig. 13. Scatterplot of cognitive and reported centrality for actor 21 with ego's position indicated.

\subsection{Example 3: low accuracy/high bias}

The two examples in this section show clearly the relationship between low knowledge and the resulting overestimate of an actor's centrality and the centrality of proximate actors. The first example is a prominent head of a department in the state government. Actor 21 has relatively low centrality in the reported network and did not attend most of the public meetings associated with the moratorium process. Fig. 13 reveals a limited knowledge of the network (QAP knowledge rank $=31, r=0.411$ ) and an inflated perception of ego's centrality (ego's residual $=-2.782$, rank difference $=-27$ ) and those of his/her direct relations. The two mangers at the top of the plot are the deputy head and assistant head of the department, while the two staff just below includes the primary staff member from the department involved in the moratorium process and a staff member who is the department's legislative liaison. Thus, in this case ego's view of the network is limited to an understanding of the relationship between ego and the immediate members of ego's department. It is important to note that actor 21 did understand, at least in part, the important structural positions of the two important actors to the far right.

One final example is included to help in further understanding the nature of bias under conditions of low accuracy. Fig. 14 is the plot of reported centrality versus cognitive centrality for actor two, a coastal legislative representative. Actor two has little knowledge of the network (QAP knowledge rank $=38, r=-0.10$ ) and an extremely large bias in perceived centrality (ego's residual $=-2.835$, rank difference $=-41$ ). What makes this actor's accuracy particularly low is his/her lack of recognition of the importance of the actors in the lower right corner of the plot. Instead, fellow legislators are accorded a much more prominent position in the network than would be justified by the reported structure. 


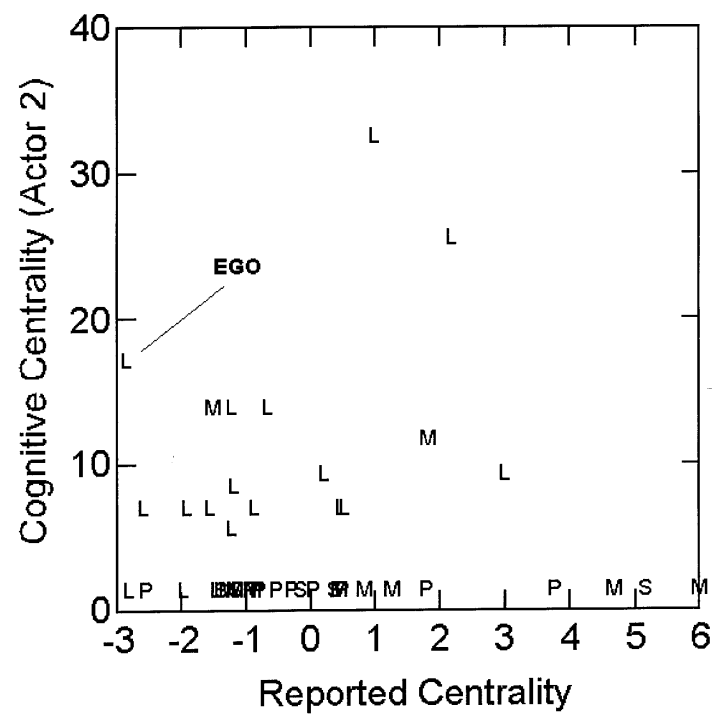

Fig. 14. Scatterplot of cognitive and reported centrality for actor two with ego's position indicated.

\section{Summary and discussion}

In keeping with other research concerning cognitive accuracy this study also finds a relationship between centrality and accuracy or knowledge of the network. This relationship was found even with the use of independent means for determining the reported network adding further credibility to the hypothesized relationship. In addition, the distribution of knowledge varied across the four statuses with the private actors having more knowledge on average than the legislators. This was further supported in a comparison of the correlations between reported and cognitive centrality across the four statuses. The private actors were the most accurate in their assessments of the centrality of all actors in the network while the legislators were the least accurate. We will speculate as to why this might be the case further along in the discussion.

As Kumbasar et al. (1994) found, there is a tendency for actors to over-estimate their centrality in the network. However, we found variation in the types of biases observed across the actors in the network. In this case, although the primary ego bias was upward (i.e. seeing themselves as more central than they really are) there were a few actors who displayed an ego bias downward (i.e. seeing themselves as less central than they really are) but to a much lesser degree. Once again, in a comparison of bias across the four statuses private actors were more likely on average to underestimate their centrality in contrast to legislators who are more likely on average to over-estimate centrality.

It is evident from the data that there is a relationship between ego bias and both centrality and knowledge of the network. Yet, as evident from the actor examples it is often the case that even in light of high accuracy an actor will exhibit high bias in judgements about his/her own centrality in the network, albeit biases of both an upward and downward nature. 
The presence of bias, even in the presence of knowledge, is in keeping with the findings of Kumbasar et al. (1994) who found bias despite attempts to control for knowledge. However, Kumbasar et al. (1994) observed almost exclusively ego biases in centrality in the upward direction. What might account for the differences between the two studies?

Certainly there are a number of differences between the two networks of interest. First, the network among the computer employees was relatively small, well bounded, and enduring in comparison to the political network. Further, employees in the computer firm had ample opportunity to observe the friendship relationships of fellow employees in a variety of work and social settings; the computer firm network can be characterized as a knowledge-rich environment. On the other hand, members of the political network had to observe interactions among other members in a more recently formed issue-oriented, weakly-bounded network in a variety of geographically dispersed social and political settings making the acquisition of network knowledge extremely challenging. Finally, the nature of the relations in the two networks, friendships and political relationships, are different in terms of the consequences of an actor's accuracy and bias in knowledge about the network. Getting it wrong in the political context can have dire consequences.

The most central actors in the reported network displayed very little bias in their assessments of their own centrality in the political network. But there were other actors who, although less central, displayed either no bias or slight bias downward in reporting their own centrality. Whereas reported centrality, as an indicator of activity in the network is important, so too is activity surrounding the attendance of meetings and public hearings. The private actors, and to a large extent managers, had the highest attendance at the various meetings and hearings associated with the moratorium process. This provided ample opportunity for these attendees to observe the interactions among the more active players in the process. On the other hand, legislators were the least likely to attend meetings and public hearings around the state (unless possibly in their own district) limiting much of their interactions with other moratorium actors to meetings and hearings in the state capital and mostly with other legislators.

Another issue concerns the extent to which this particular issue-oriented network is the focus of an actor's efforts. For many of the private actors, the issues surrounding the license moratorium are of primary importance. Particularly for some of the executive directors of fisheries interest groups, the moratorium legislative process constitutes the bulk of their lobbying efforts. Legislators, on the other hand, are engaged in multiple issue networks surrounding a variety of political concerns. In addition, the legislature is less involved in the moratorium process at this stage in the network's evolution. The legislators will be much more involved in the process in the future when legislation is slated to be developed based on the recommendations of the Moratorium Steering Committee.

Thus, we might venture to say that legislators may over-estimate centrality for a variety of reasons. First, legislators are in fact important, not just in terms of the eventual development and consideration of legislation related to the moratorium, but also with respect to a vast array of other important legislative and political matters and this may be reflected in their assessments, even for knowledgeable legislators. Second, given limited opportunities to observe players in the network at this early stage in the process, legislators (and some managers) must rely on what little knowledge is available to them which will tend to inflate the importance of ego and his/her proximate relations. 


\section{Concluding remarks}

One of the interesting challenges of these findings is to provide a reasonable theoretical explanation for what was observed. Brewer (2000) and Krebs and Denton (1997) have recently suggested biases in social perception of the upward kind (e.g. status, motivations) may increase fitness by fostering self-fulfilling prophecies. These self-fulfilling prophecies contribute to the formation of adaptive behaviors that fall in line with individual perceptions. In addition, these upwardly biased self-perceptions are unconscious, possibly contributing to the believability of an ego's biased self-image as perceived by others.

Whereas the above idea may be reasonable for explaining ego biases upward, they fail to account for downward biases, however rare they may be. Hartung (1988) observed self-deception downward among individuals with little hope of advancement in status. The comparative psychological process is similar to that above, but in the opposite direction. Finding an inconsistency between actual status and desired or perceived status, individuals will reconcile this difference through self-deception by lowering their self-image. This diminishes the tension between the real and perceived. In addition, Hartung argues that such a downward adjustment in perception is adaptive in that it diminishes tensions between superiors and subordinates leading to a variety of positive outcomes (e.g. more emotional and social security).

The two possible explanations above for observed biases primarily view the development of these adaptive self-perceptions as an unconscious process. It is probably the case that these processes are, in fact, largely unconscious for it is hard to imagine that humans are capable of consistently engaging in conscious efforts to fool people, with the possible exception of the occasional con artist, sociopath, or professional actor/actress. But what about the world of politics? The political arena is definitely a world full of both self-deception and other deceptions of various kinds (although we do not intend to imply that politicians are sociopaths). Are these deceptions carried out in a conscious or unconscious manner? The answer to this is more than likely both, since the nature of political intrigue involves both conscious and unconscious perceptions and actions on the part of political actors (e.g. political deal-making carried out in smoke-filled back rooms).

Following the arguments of Brewer (2000) and Krebs and Denton (1997) it's not hard to argue the adaptive value of inflated self-esteem among legislators. One can imagine that by believing and behaving (within some reasonable limits) as if he/she has more political capital than he/she really has, a legislator may lead others to believe similarly actually enhancing the legislator's political reputation. But this kind of argument would not explain the downward biases of some of the non-legislative actors.

However, there is a complementary explanation that might account for the variation in ego bias observed in the political network. Since legislators are the actors who ultimately determine the legislative outcome, there will be attempts on the part of various non-legislative others to influence legislators. The effectiveness of non-legislators in influencing the outcome depends on their ability to be convincing that their particular position is legitimate and/or politically expedient. This interaction creates a dyadic relation similar to that described by Hartung (1988) between individuals of higher and lower status. The problem lies in the presentation of self on the part of individuals involved in the dyadic interaction. If the higher status legislator is already engaged in bias upward behavior, whether 
conscious or unconscious, is it in the best interest of the lower status actor to respond in kind? Self-perception downward may have the adaptive benefit of leading the lower status actor to behave in a convincingly deferent manner that may lead to more positive outcomes (e.g. more willingness on the part of the legislator to help the lobbyist). Such a self-image on the part of non-legislators may ultimately influence the assessment of an ego's centrality in the political network.

These possible explanations are intriguing, but are beyond the scope of the present paper. We end in a manner similar to Kumbasar et al. (1994, p. 502) in calling for more work that will help "catalogue the various ego biases and explore their consequences in the formation and maintenance of social groups." We submit the example presented here as one more entry in the catalogue. In keeping with this call, future research should examine these phenomena in a wider range of both social and political settings where social knowledge and biases may have real consequences for such things as, for example, power and the development of social capital. In addition, efforts should be made to examine the evolution of biases in networks in order to gain a better understanding of the role of knowledge in the formation and maintenance of ego biases.

\section{Acknowledgements}

This work was sponsored by a grant from the University of North Carolina Sea Grant College Program. We would like to thank all the participants in the study for their cooperation and patience.

\section{References}

Bernard, H.R., Killworth, P.D., 1977. Informant accuracy in social network data II. Human Communications Research 4 (1), 3-18.

Bernard, H.R., Killworth, P.D., Sailer, L., 1980. Informant accuracy in social network data IV: a comparison of clique-level structure in behavioral and cognitive data. Social Networks 2, 191-218.

Bernard, H.R., Killworth, P.D., Sailer, L., 1982. Informant accuracy in social network data V: an experimental attempt to predict actual communication from recall data. Social Science Research 11, 30-66.

Borgatti, S.P., Everett, M.G., Freeman, L.C., 1999. Ucinet for windows: software for social network analaysis, Analytic Technologies, Natick.

Boster, J.S., Johnson, J.C., Weller, S.C., 1987. Social position and shared knowledge: actor's perceptions of status, role and social structure, role and social structure. Social Networks 9, 375-387.

Brass, D.J., 1985. Men's and women's networks: a study of interaction patterns and influence in an organization. Academy of Management Journal 28, 518-539.

Brewer, D.D., 2000. Biases in perceiving one's own social position and social ties as evolved psychological mechanisms. In: Proceedings of the Presentation on Social Theory and Networks on Ethnography at the Cologne 2000 Conference, July 2000.

Cogan, L.C., Conklin, A.M., Hollingworth, H.L., 1915. An experimental study of self-analysis, estimates of associates, and the results of tests. School and Society 2, 171-179.

Eudey, L., Johnson, J.C., Schade, E., 1994. Ranking versus ratings in social networks: theory and praxis. Journal of Qualitative Anthropology 4, 297-312.

Freeman, L.C., Romney, A.K., 1987. Words, deeds and social structure: a preliminary study of the reliability of informants. Human Organization 46 (4), 330-334. 
Freeman, L.C., Webster, C.M., 1994. Interpersonal proximity in social and cognitive space. Social Cognition 12 (3), 223-231.

Freeman, L.C., Romney, A.K., Freeman, S.C., 1987. Cognitive structure and informant accuracy. American Anthropologist 89, 310-325.

Hartung, J., 1988. Deceiving down: conjectures on the management of subordinate status. In: Stockard, J.S., Paulhus, D.L. (Eds.), Self-Deception: An Adaptive Mechanism?, Prentice Hall, Englewood Cliffs, NJ, pp. 170-181.

Hubert, L., Schultz, J., 1976. Quadratic assignment as a general data analysis strategy. British Journal of Mathematical and Statistical Psychology 29, 190-241.

Iannucci, A.L., 1991. Patterns of consensus and divergence in the judgement of personality traits among a group of well-acquainted young women. Unpublished doctoral dissertation, University of California, Irvine.

Johnson, J.C., Orbach, M.K., 1996. Effort Management in North Carolina Fisheries: A Total Systems Approach, University of North Carolina Sea Grant, Raleigh, UNC-SG-96-08, p. 258.

Killworth, P.D., Bernard, H.R., 1976. Informant accuracy in social network data. Human Organization 35 (3), 269-286.

Killworth, P.D., Bernard, H.R., 1979/1980. Informant accuracy in social network data III: a comparison of triadic structure in behavioral and cognitive data. Social Networks 2, 10-46.

Krackhardt, D., 1987. Cognitive social structures. Social Networks 9, 109-134.

Krackhardt, D., 1990. Assessing the political landscape: structure, cognition, and power in organizations. Administrative Science Quarterly 35, 342-369.

Krebs, D.L., Denton, K., 1997. Social illusions and self-deception: the evolution of biases in person perception. In: Simpson, J.A., Kenrick, D.T. (Eds.), Evolutionary Social Psychology, Erlbaum, Mahwah, NJ, pp. 21-47.

Kumbasar, E., Romney, A.K., Batchelder, W., 1994. Systematic biases in social perception. American Journal of Sociology 100 (2), 477-505.

Omark, D.R., Omark, M., Edelman, M., 1975. Formation of dominance hierarchies in young children. In: Williams, T.R. (Ed.), Psychological Anthropology, Mouton, The Hague, pp. 289-315.

Romney, A.K., Faust, K., 1982. Predicting the structure of a communications network from recalled data. Social Networks 4, 285-304.

Romney, A.K., Weller, S., 1984. Predicting informant accuracy from patterns of recall among individuals. Social Networks 6, 59-78.

Ross, M., Sicoly, F., 1979. Egocentric biases in availability and attribution. Journal of Personality and Social Psychology 37, 322-336.

Warner, W.L., Meeker, M., Eells, K., 1960. Social Class in America, Harper \& Bros, New York.

Webster, C.M., 1995. Detecting context-based constraints in social perception. Journal of Quantitative Anthropology 5, 285-303. 